\title{
Letter \\ Video of dantrolene effectiveness on neuroleptic malignant syndrome associated muscular rigidity and tremor
}

\author{
Miran Brvar ${ }^{1,2}$ and Matjaz Bunc ${ }^{2,3}$
}

\author{
${ }^{1}$ Poison Control Centre, University Medical Centre Ljubljana, Ljubljana, Slovenia \\ 2Institute for Pathophysiology, Medical Faculty, Zaloska cesta 4, 1000 Ljubljana, Slovenia \\ ${ }^{3}$ Department for Cardiology, University Medical Center Ljubljana, Zaloska cesta 7, Ljubljana, Slovenia
}

Corresponding author: Miran Brvar, miran.brvar@kclj.si

Published: 1 June 2007

This article is online at http://ccforum.com/content/11/3/415

(c) 2007 BioMed Central Ltd
Critical Care 2007, 11:415 (doi:10.1186/cc5907)
Neuroleptic malignant syndrome (NMS) is an uncommon but potentially fatal adverse reaction to neuroleptic drugs, including amisulpride [1,2]. NMS most commonly presents with increased body temperature, muscular rigidity of a 'lead pipe' nature, altered mental status and autonomic dysfunction. Other extrapyramidal movement disorders such as tremor and cogwheel phenomena are also frequently present. The treatment of NMS includes discontinuation of contributing drugs and supportive therapy, but specific treatment with dantrolene, bromocriptine, nondepolarizing neuromuscular paralysis and benzodiazepines, among other such agents, has been reported only anecdotally. A recent analysis of published case reports [3] evaluated the efficacy of dantrolene in NMS; it found that dantrolene, given as monotherapy, might be helpful in managing this syndrome if the premedication was a neuroleptic monotherapy. We present video evidence of the effectiveness of dantrolene in reducing muscular rigidity, tremor and cogwheel phenomena in a patient with NMS.

Amisulpride therapy was initiated in a 79-year-old patient with a schizoaffective disorder. After 10 days the patient became somnolent with a high body temperature $\left(40.3^{\circ} \mathrm{C}\right)$, diaphoresis, tachycardia, rigid skeletal muscles of a 'lead pipe' character, cogwheel phenomena and resting tremor (video footage is available in Additional data file 1). Laboratory results revealed creatine kinase to be $15.1 \mu \mathrm{kat} / \mathrm{l}$ and myoglobin to be $8,654 \mu \mathrm{g} / \mathrm{l}$, indicating rhabdomyolysis. Blood urea nitrogen was $11.6 \mathrm{mmol} / \mathrm{l}$ and creatine was $139 \mu \mathrm{mol} / \mathrm{l}$, indicating renal failure that probably was caused by dehydration. Procalcitonin was within normal limits, excluding infection. A brain computed tomography scan and lumbar puncture findings were normal. NMS caused by treatment with amisulpride was suspected and it was discontinued.

External cooling with sponging and fanning was started. Bromocriptine, a dopamine agonist, was introduced at a dose of $5 \mathrm{mg}$ every 8 hours through a nasogastric tube, but after
1 day there was no clinical improvement and so bromocriptine was withdrawn. Then, $60 \mathrm{mg}(1 \mathrm{mg} / \mathrm{kg})$ dantrolene was administered intravenously over $5 \mathrm{~min}$. Muscle rigidity, cogwheel phenomena and tremor disappeared within $10 \mathrm{~min}$ (video footage is available in Additional file 2), but they gradually reappeared within an hour. The dantrolene infusion was repeated three times within 12 hours and body temperature gradually decreased to $37.5^{\circ} \mathrm{C}$. Bromocriptine therapy was continued two more days. The patient's level of consciousness improved and signs of NMS disappeared during subsequent days.

The diagnosis of NMS in this patient is based on identifying the characteristic clinical manifestations in association with a typical history of therapy with amisulpride, which antagonizes dopaminergic $D_{2} / D_{3}$ receptor subtypes. The patient also developed renal failure, which may participate in amisulpride accumulation because amisulpride is eliminated unchanged in urine.

Dantrolene might be useful in managing skeletal muscle rigidity because it relaxes skeletal muscles by inhibiting release of calcium from the sarcoplasmic reticulum, thereby reducing actin-myosin contractile activity. In the videos presented (Additional data files 1 and 2) the effect of dantrolene on muscular rigidity of a 'lead pipe' nature, cogwheel phenomena and tremor are clearly visible. However, the usefulness of dantrolene in NMS remains questionable, and this is but one of a number of anecdotal reports. Nevertheless, it offers an additional visual impression of the effectiveness of dantrolene on rigidity and tremor caused by NMS.

To conclude, we speculate that prompt reduction in NMSassociated muscular rigidity by dantrolene contributed to a decrease in body temperature. Our reporting of this case was approved by the Hospital Committee for Medical Ethics (University Medical Centre Ljubljana). 


\section{Additional files}

The following Additional file(s) for this article are available online:

\section{Additional file 1}

A video file showing rigid skeletal muscles of a 'lead pipe' nature, cogwheel phenomena and resting tremor in a patient with NMS caused by amisulpride treatment.

http://ccforum.com/content/supplementary/cc5907-s1.mov

\section{Additional file 2}

A video file showing skeletal muscle hypotonia without cogwheel phenomena and tremor after dantrolene treatment in a patient with NMS caused by amisulpride treatment.

http://ccforum.com/content/supplementary/cc5907-s2.mov

\section{Competing interests}

The authors declare that they have no competing interests.

\section{Acknowledgement}

Written consent for publication was obtained from the patient.

\section{References}

1. Atbasoglu EC, Ozguven HD, Can Saka M, Goker C: Rhabdomyolysis and coma associated with amisulpride: a probable atypical presentation of neuroleptic malignant syndrome. J Clin Psychiatry 2004, 65:1724-1725.

2. Bottlender R, Jager M, Hofschuster E, Dobmeier P, Moller HJ: Neuroleptic malignant syndrome due to atypical neuroleptics: three episodes in one patient. Pharmacopsychiatry 2002, 35: 119-121.

3. Reulbach U, Dutsch C, Biermann T, Sperling W, Thuerauf N, Kornhuber J, Bleich S: Managing an effective treatment for neuroleptic malignant syndrome. Crit Care 2007, 11:R4. 